\title{
Arterial Supply to the Rotator Cuff Muscles
}

\author{
Suministro Arterial de los Músculos del Manguito Rotador \\ N. Naidoo*; L. Lazarus*; B. Z. De Gama*; N. O. Ajayi" \& K. S. Satyapal*
}

\begin{abstract}
NAIDOO, N.; LAZARUS, L.; DE GAMA, B. Z.; AJAYI, N. O. \& SATYAPAL, K. S. Arterial supply to the rotator cuff muscles.Int. J. Morphol., 32(1):136-140, 2014.

SUMMARY: The arterial supply to the rotator cuff muscles is generally provided by the subscapular, circumflex scapular, posterior circumflex humeral and suprascapular arteries. This study involved the bilateral dissection of the scapulohumeral region of 31 adult and 19 fetal cadaveric specimens. The subscapularis muscle was supplied by the subscapular, suprascapular and circumflex scapular arteries. The supraspinatus and infraspinatus muscles were supplied by the suprascapular artery. The infraspinatus and teres minor muscles were found to be supplied by the circumflex scapular artery. In addition to the branches of these parent arteries, the rotator cuff muscles were found to be supplied by the dorsal scapular, lateral thoracic, thoracodorsal and posterior circumflex humeral arteries. The variations in the arterial supply to the rotator cuff muscles recorded in this study are unique and were not described in the literature reviewed. Due to the increased frequency of operative procedures in the scapulohumeral region, the knowledge of variations in the arterial supply to the rotator cuff muscles may be of practical importance to surgeons and radiologists.
\end{abstract}

\section{KEY WORDS: Arterial supply; Variations; Rotator cuff muscles; Parent arteries.}

\section{INTRODUCTION}

The rotator cuff is a musculotendionous cuff formed by the fusion of the tendons of four muscles - viz. supraspinatus, infraspinatus, teres minor and subscapularis, with the fibrous capsule of the glenohumeral joint (Standring et al., 2008). The supraspinatus, infraspinatus and teres minor muscles originate from the dorsal surface of the scapula and insert onto the greater humeral tubercle, while the subscapularis muscle arises from the anterior surface of the scapula and inserts onto the lesser tubercle of the humerus (Muscolino, 2010).

The vascular supply to the rotator cuff muscles is chiefly via the suprascapular and subscapular arteries and their relevant branches. This classic description has been reported by many authors (Maral et al., 1993; Determe et al., 1996; Abrassart et al., 2006; Standring et al.). Determe et al., observed that the suprascapular artery supplied the supraspinatus muscle. The suprascapular artery then descended from the supraspinous fossa to the infraspinous fossa where it also provided a branch to the infraspinatus muscle
(Abrassart et al.). In addition, the muscular parts of infraspinatus and teres minor muscles were supplied by the circumflex scapular artery while the tendinous parts of these muscles received branches from the posterior circumflex humeral artery (Determe et al.). Standring et al. confirmed that the subscapularis muscle was supplied by the suprascapular and subscapular arteries.

The arterial supply is especially important for the adequate perfusion to the watershed region of the rotator cuff tendons, which is generally an area of weak vascular supply and therefore prone to injury. The aim of this study was to describe the arterial supply to the rotator cuff muscles.

\section{MATERIAL AND METHOD}

The arterial supply to the rotator cuff muscles was investigated through the bilateral macroscopic and microscopic dissection of the upper arm regions in fifty cadaveric specimens, of which thirty-one were adults and nineteen were fetuses. This study was performed in

* Department of Clinical Anatomy School of Laboratory Medicine and Medical Sciences College of Health Sciences University of KwaZulu-Natal, Durban, South Africa. 
accordance with Chapter 8 of the National Health Act No. 61 of 2003 at the Department of Clinical Anatomy, University of KwaZulu-Natal, Durban, South Africa. Ethical approval was granted by the relevant institutional authority (Ethical Clearance Approval Number: LMMSEC 003/12). The rotator cuff muscles were dissected and the arterial supply to each individual muscle was observed and noted. Micro dissection was achieved through the use of a micro dissector and a microscope (Stemi DV4 by Carl Zeiss AG, Germany).

Statistical analysis included the comparisons of laterality as well as that of fetal and adult subsets. The data was analyzed using SPSS version 19.0 (SPSS Inc., Chicago, Illinois, USA). A p value of $<0.05$ was considered to be statistically significant.

\section{RESULTS}

The Subscapularis Muscle. The subscapularis muscle was supplied by the suprascapular artery in thirty-six specimens $\mathrm{n}=36 / 100$ (36\%) (right 18/50; left 18/50) (Table I) and by the subscapular artery in ninety-six specimens $n=96 / 100$ (96\%) (right 48/50; left 48/50) (Table I). In nine specimens the circumflex scapular artery supplied the subscapularis muscle $n=9 / 100$ (9\%) (right 5/50; left 4/50) (Table I). The subscapularis muscle was supplied by thoracodorsal artery

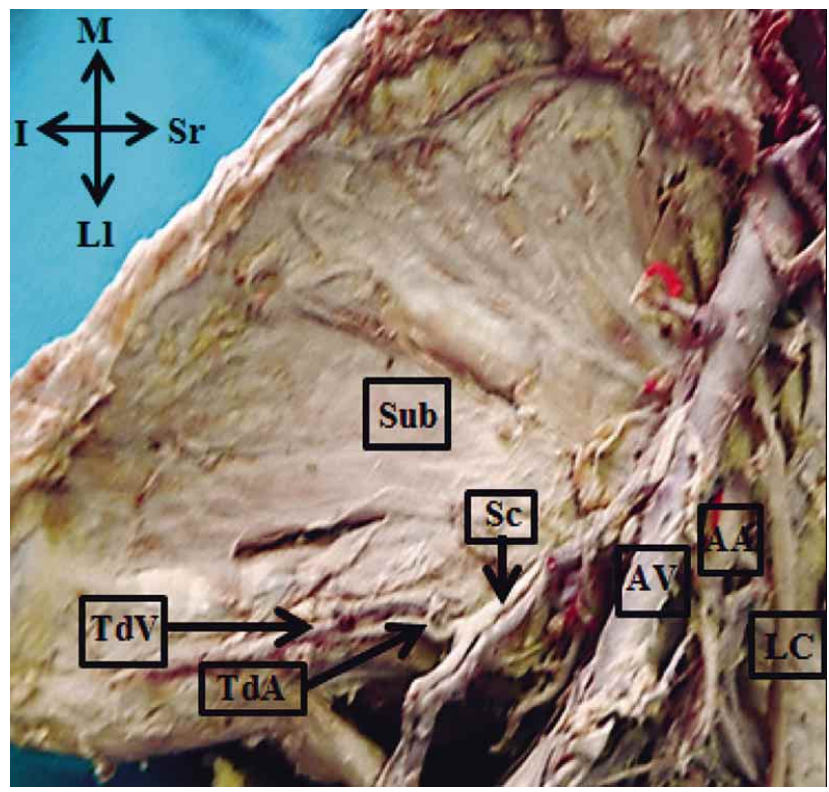

Fig. 1. Thoracodorsal artery supplying the subscapularis muscle. Key: AA= Axillary artery; $\mathrm{AV}=$ Axillary vein; $\mathrm{I}=$ Inferior; $\mathrm{LC}=$ Lateral cord of brachial plexus; $\mathrm{Ll}=$ Lateral; $\mathrm{M}=$ Medial; $\mathrm{Sc}=$ Subscapular artery; $\mathrm{Sr}=$ Superior; $\mathrm{Sub}=$ Subscapularis muscle; $\mathrm{TdA}=$ Thoracodorsal artery; $\mathrm{TdV}=$ Thoracodorsal. in thirty-nine specimens $n=39 / 100$ (39\%) (right 11/50; left 28/50) (Table I; Fig. 1), whereas the lateral thoracic artery supplied it in fourteen specimens $n=14 / 100(14 \%)$ (right 6/ 50; left 8/50) (Table I; Fig. 2). In addition, the posterior circumflex humeral artery supplied the subscapularis muscle in four specimens $n=4 / 100(4 \%)$ (right 1/50; left 3/50) (Table I; Fig. 3).

The Supraspinatus Muscle. The supraspinatus muscle was supplied by the suprascapular artery in all specimens (Table I). The dorsal scapular artery supplied the supraspinatus muscle in four specimens $n=4 / 100$ (4\%) (right 2/50; left $2 /$ 50) (Table I; Fig. 4).

The Infraspinatus Muscle. The infraspinatus muscle was identified to be supplied by the circumflex scapular artery in eighty-one specimens $n=81 / 100$ (81\%) (right 40/50; left 41/50) (Table I). Ninety-four specimens were seen to be supplied by the suprascapular artery $n=94 / 100(94 \%)$ (right 49/50; left 45/50) (Table I).

The Teres Minor Muscle. The muscular aspect of the teres minor muscle was found to be supplied by the circumflex scapular artery in all specimens (Table I). The posterior circumflex humeral artery supplied the tendinous aspect of the teres minor muscle in eight specimens $\mathrm{n}=8 / 100(8 \%)$ (right 4/50; left 4/50) (Table I). The comparison of fetal and adult subsets presented with a p value of 0.030 (Table II).

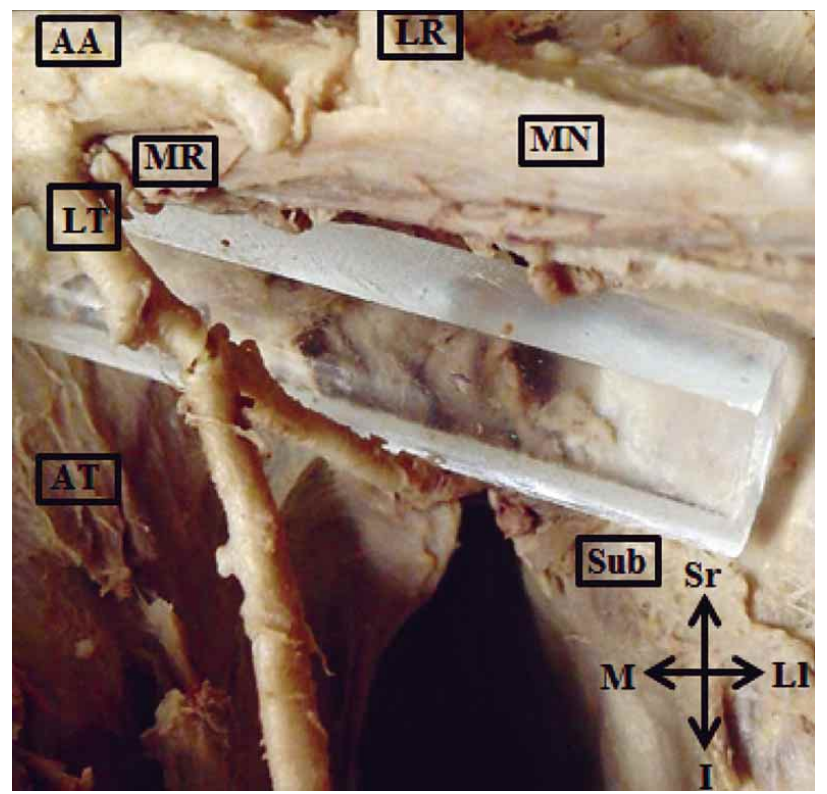

Fig. 2. Lateral Thoracic artery supplying the subscapularis muscle. Key: AA= Axillary artery; AT = Anterior thoracic wall; $\mathrm{I}=$ Inferior; $\mathrm{Ll}=$ Lateral; LR= Lateral root of brachial plexus; $\mathrm{LT}=$ Lateral thoracic artery; $\mathrm{M}=$ Medial; $\mathrm{MN}=$ Median nerve; $\mathrm{MR}=$ Medial root of median nerve; $\mathrm{Sr}=$ Superior; Sub= Subscapularis muscle. 


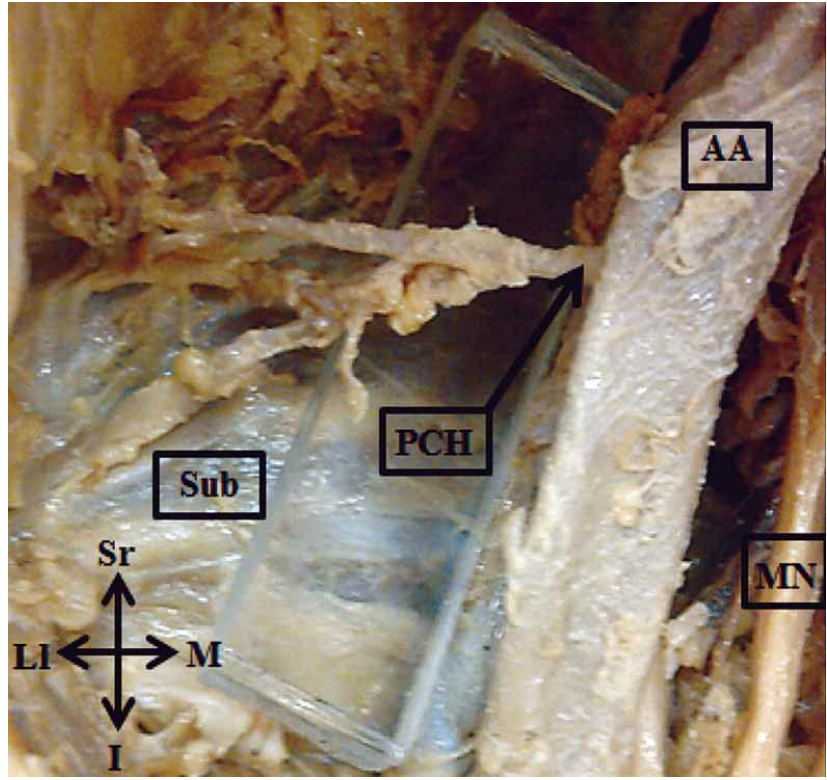

Fig. 3. Posterior circumflex humeral artery supplying the subscapularis muscle.

Key: AA= Axillary artery; I= Inferior; $\mathrm{Ll}=$ Lateral; $\mathrm{M}=$ Medial; $\mathrm{MN}=$ Median nerve; $\mathrm{PCH}=$ Posterior circumflex humeral artery; $\mathrm{Sr}=\mathrm{Superior}$; $\mathrm{Sub}=$ Subscapularis muscle.

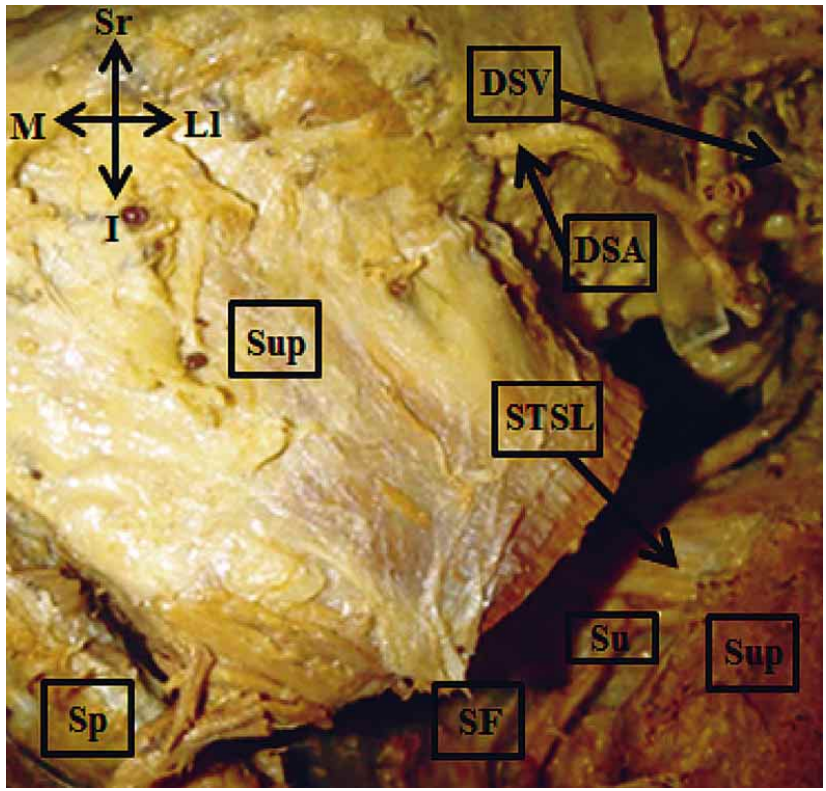

Fig. 4. Dorsal scapular artery supplying the supraspinatus muscle. Key: DSA= Dorsal scapular artery; $\quad$ DSV= Dorsal scapular vein; I= Inferior; $\mathrm{Ll}=$ Lateral; $\mathrm{M}=$ Medial; $\mathrm{SF}=$ Supraspinous fossa; $\mathrm{Sp}=\mathrm{Spine}$ of scapula; $\mathrm{Sr}=$ Superior; $\mathrm{Su}=$ Suprascapular artery; Sup= Supraspinatus muscle; STSL= Superior transverse scapular ligament.

Table I. Incidence ( $\mathrm{n}$ of specimens) of arteries supplying the rotator cuff muscles in adults \& fetuses $(\mathrm{n}=100)$.

\begin{tabular}{|c|c|c|c|c|c|}
\hline \multirow[t]{2}{*}{ Artery } & \multirow[t]{2}{*}{ Side } & \multicolumn{4}{|c|}{ Muscles } \\
\hline & & Subscapularis & Supraspinatus & Infraspinatus & Teres Minor \\
\hline \multirow[t]{3}{*}{ Suprascapular } & Right & 18 & 50 & 49 & 0 \\
\hline & Left & 18 & 50 & 45 & 0 \\
\hline & Total & 36 & 100 & 94 & 0 \\
\hline \multirow[t]{3}{*}{ Subscapular } & Right & 48 & 0 & 0 & 0 \\
\hline & Left & 48 & 0 & 0 & 0 \\
\hline & Total & 96 & 0 & 0 & 0 \\
\hline \multirow[t]{3}{*}{ Thoracodorsal } & Right & 11 & 0 & 0 & 0 \\
\hline & Left & 28 & 0 & 0 & 0 \\
\hline & Total & 39 & 0 & 0 & 0 \\
\hline \multirow[t]{3}{*}{ Lateral Thoracic } & Right & 6 & 0 & 0 & 0 \\
\hline & Left & 8 & 0 & 0 & 0 \\
\hline & Total & 14 & 0 & 0 & 0 \\
\hline \multirow[t]{3}{*}{ Circumflex Scapular } & Right & 5 & 0 & 40 & 50 \\
\hline & Left & 4 & 0 & 41 & 50 \\
\hline & Total & 9 & 0 & 81 & 100 \\
\hline Posterior & Right & 1 & 0 & 0 & 4 \\
\hline Circumflex & Left & 3 & 0 & 0 & 4 \\
\hline Humeral & Total & 4 & 0 & 0 & 8 \\
\hline \multirow[t]{3}{*}{ Dorsal Scapular } & Right & 0 & 2 & 0 & 0 \\
\hline & Left & 0 & 2 & 0 & 0 \\
\hline & Total & 0 & 4 & 0 & 0 \\
\hline
\end{tabular}


Table II. P Values reflecting the level of significance of the comparisons of right and left shoulders and that of adult and fetal subsets.

\begin{tabular}{|c|c|c|}
\hline \multirow[b]{2}{*}{ Muscle } & \multicolumn{2}{|c|}{ P Values } \\
\hline & Comparison of right and left sides & Comparison of adult and fetal subsets \\
\hline Subscapularis & 0.232 & 0.325 \\
\hline Supraspinatus & 1.000 & 0.122 \\
\hline Infraspinatus & 0.717 & 0.609 \\
\hline Teres Minor & 1.000 & 0.030 \\
\hline
\end{tabular}

\section{DISCUSSION}

The subscapularis muscle appeared to be supplied by the suprascapular artery in $96 \%$ of specimens which corroborated the findings of Standring et al. In addition, Standring et al. also stated that the subscapular artery supplied the subscapularis muscle, which was seen in $36 \%$ of specimens of the present study. The circumflex scapular artery was observed to supply the subscapularis muscle in $9 \%$ of specimens as described by Maral et al. Subsequently, the subscapularis muscle was supplied by the thoracodorsal artery in $39 \%$ of specimens, the lateral thoracic artery in $14 \%$ of specimens and the posterior circumflex humeral artery in $4 \%$ of specimens. These observations appear to be unique, as they are not described in the literature reviewed. There were no statistically significant differences between sides nor was there a difference in arterial supply between fetuses and adults.

In all the specimens $(100 \%)$ the supraspinatus muscle was supplied by the suprascapular artery as described by Determe et al. In addition, the dorsal scapular artery was seen to supply the supraspinatus muscle in $4 \%$ of specimens, an observation that was not described in the literature reviewed.

Determe et al. stated that the infraspinatus muscle was supplied by the circumflex scapular artery, which was observed in $81 \%$ of specimens in the present study. In $94 \%$ of specimens the infraspinatus muscle was supplied by the suprascapular artery. This observation corroborated the findings of Abrassart et al. who stated that the suprascapular artery descended from the supraspinous fossa to the infraspinous fossa where it provided a branch to the infraspinatus muscle.

The muscular aspect of the teres minor muscle was supplied by the circumflex scapular artery in all specimens as reported by Determe et al. In $8 \%$ of specimens, the posterior circumflex humeral artery supplied the tendinous aspect of the teres minor muscle concurring with the study conducted by Determe et al. A statistically significant $\mathrm{p}$ value of 0.030 was recorded between fetal and adult subsets for the arterial supply of the teres minor muscle only.

Many branches of the parent arteries - viz. thyrocervical trunk and subscapular artery, have been identified to contribute to the vascularity of the rotator cuff muscles. The aforementioned branches include the suprascapular, circumflex scapular and thoracodorsal arteries. As the parent arteries play a major role in the formation of the collateral circulation, variation in the arterial supply to the rotator cuff muscles may result in arterial insufficiency of the upper limb.

\section{CONCLUSION}

The arterial supply to the rotator cuff muscles compared favorably with the described literature (Determe et al.; Standring et al.). The subscapularis muscle was traditionally supplied by the subscapular (36\%), suprascapular (96\%) and circumflex scapular (9\%) arteries. The suprascapular artery accounted for the main arterial supply to the supraspinatus (100\%) and infraspinatus (94\%) muscles. The circumflex scapular artery provided the additional blood supply to the infraspinatus (81\%) and teres minor $(100 \%)$ muscles.

This study also documented several variations in the arterial supply to the rotator cuff muscles which are not reported in previous literature. The subscapularis muscle was unusually supplied by the thoracodorsal (39\%), lateral thoracic (14\%) and posterior circumflex humeral (4\%) arteries, while the supraspinatus muscle was found to be supplied by the dorsal scapular artery (4\%).

The complexity of the vascular anatomy of the rotator cuff unit may require re-evaluation in order to assess and treat injuries in this region. 
NAIDOO, N.; LAZARUS, L.; DE GAMA, B. Z.; AJAYI, N. O. \& SATYAPAL, K. S. Suministro arterial de los músculos del manguito rotador. Int. J. Morphol., 32(1):136-140, 2014.

RESUMEN: El suministro arterial a los músculos del manguito rotador generalmente es proporcionado por las arterias subescapular, circunfleja escapular, circunfleja humeral posterior y supraescapular. Se realizó la disección bilateral de la región escapulo humeral de 31 especímenes cadavéricos adultos y 19 fetos. El músculo subescapular estaba irrigado por las arterias subescapular, supraescapular y circunfleja escapular. Por otra parte, la arteria supraescapular irrigaba a los músculos supra e infraespinoso. Observamos que los músculos infraespinoso y redondo menor fueron irrigados por la arteria circunfleja escapular. Además de las arterias de origen y sus ramas, observamos que los músculos del manguito rotador son irrigados por la arteria escapular dorsal y las arterias torácica lateral, toracodorsal y circunfleja humeral posterior. Las variaciones en la irrigación de los músculos del manguito rotador registrados en este estudio son únicos y no existe una descripción referente a ellos en la literatura revisada. Debido a la mayor frecuencia de los procedimientos quirúrgicos en la región escápulohumeral, el conocimiento de las variaciones de la irrigación de los músculos del manguito rotador puede ser de importancia práctica para cirujanos y radiólogos.

PALABRAS CLAVE: Irrigación arterial; Variaciones; Músculos del manguito rotador; Arterias.

\section{REFERENCES}

Abrassart, S.; Stern, R. \& Hoffmeyer, P. Arterial supply of the glenoid: An anatomic study. J. Shoulder Elbow Surg., 15(2):232-8, 2006.

Determe, D.; Rongieres, M.; Kany, J.; Glasson, J. M.; Bellumore, Y.; Mansat, M. \& Becue, J. Anatomic study of the tendinous rotator cuff of the shoulder. Surg. Radiol. Anat., 18(3):195200, 1996.

Maral, T.; Celik, H.; Hayran, M. \& Kecik, A. An anatomical variation of the thoracodorsal artery with comments on flaps based on the axillary artery. Eur. J. Plast. Surg., 16(4-5):231$3,1993$.

Muscolino, J. E. The Muscular System Manual: The Skeletal Muscles of the Human Body. $3^{\text {rd }}$ ed. Missouri, Mosby Inc., 2010.

Standring, S. Gray's Anatomy: The Anatomical Basis of Clinical Practice. $40^{\text {th }}$ ed. Philadelphia, Elsevier Ltd., 2008.

\author{
Correspondence to: \\ Professor K. S. Satyapal \\ Department of Clinical Anatomy \\ School of Laboratory Medicine and Medical Sciences \\ College of Health Sciences \\ University of KwaZulu-Natal \\ Private Bag X54001 \\ Durban, 4000 \\ SOUTH AFRICA
}

Telephone: +27 31260 7110; + 27837778780

Fax: +27 312607890

Email: satyapalk@ukzn.ac.za

Received: 03-10-2013

Accepted: 13-12-2013 